\title{
EVOLUÇÃO DAS PROPRIEDADES DOS SOLOS POR DIFERENTES PRÁTICAS AGRÍCOLAS NO SUDESTE PARAENSE
}

\author{
Sanny Juslley de Souza Araujo ${ }^{1}$; Michel Grimaldi ${ }^{2}$ \\ ${ }^{1}$ Discente do curso de Agronomia, Faculdade de Ciências Agrárias de Marabá (FCAM), Universidade Federal do Pará \\ (UFPA), Marabá, Pará. Bolsista do projeto AMAZ. E-mail: sannyjuslley@ hotmail.com. \\ ${ }^{2}$ Pesquisador do Institut de Recherche pour le Développmente - IRD. E-mail: michel.grimaldi@ird.fr.
}

\begin{abstract}
RESUMO: O ecossistema da Amazônia é frágil. Os solos são pobres e a floresta vive de seu próprio material orgânico. $\mathrm{O}$ ambiente úmido e as chuvas abundantes dependem da vegetação natural. O equilíbrio é instável, sua preservação complexa, e os conhecimentos sobre a biodiversidade, a terra, as águas e os homens são escassos. A floresta Amazônica è a base do sustento de milhões de pessoas, e particularmente de agricultores familiares que aqui vieram em busca de uma vida melhor. As atividades destes agricultores influenciam os serviços ambientais realizados pelo meio ambiente Amazônico. No entanto, esta influência não acontece da mesma maneira para todos. Diferentes tipos de famílias, com atividades diferentes, têm impactos diferentes sobre o meio ambiente e sobre os serviços por ele prestados. As práticas adotadas no manejo das atividades agrícolas influenciam diretamente na sustentabilidade dos solos das áreas colonizadas, e na modificação da cobertura vegetal transformando solos férteis e produtivos em inférteis e improdutivos, se não forem conduzidas dentro de critérios técnicos preestabelecidos. Devido a isso, a preocupação de uma utilização verdadeiramente racional do uso da terra tem proporcionado nos últimos tempos, uma busca de metodologia adequada que expresse as potencialidades do meio e que represente um aproveitamento equilibrado do ecossistema. O objetivo desse trabalho será avaliar os impactos da transformação do meio ambiente pelos agricultores familiares sobre as propriedades físicas e químicas do solo, em função dos sistemas de produção, das práticas culturais e dos solos que se encontram na região sudeste do Pará. Serão analisadas as variáveis sócioeconômicas dos estabelecimentos agrícolas e as variáveis pedológicas. Os dados serão coletados em 27 propriedades pertencentes aos projetos de assentamento PA Palmares II em Parauapebas- PA, PA Agro-extrativista Praialta Piranheira em Nova Ipixuna-PA, Travessão 338 Sul em Pacajá-PA. Tais variáveis são: histórico da área, produções, itinerários técnicos, trajetória da família, patrimônio/capital produtivo e sua evolução, uso do solo, mão-de-obra, meio ambiente e serviços ambientais. Essas variáveis serão obtidas através de questionários Agro-sócio-econômico elaborado pelo projeto AMAZ. As variáveis pedológicas a serem avaliadas serão: características intrínsecas do solo (do meio físico); declividade e profundidade útil do solo; granulometria, ou seja, quantidade de argila, silte, areia; características químicas $\left(\mathrm{pH}, \mathrm{Al}^{3+}, \mathrm{SB}, \mathrm{Ca}, \mathrm{Mg}, \mathrm{K}, \mathrm{CTC}, \mathrm{V}, \mathrm{P}, \mathrm{NH}_{4}\right)$, físicas (densidade, infiltração da água, resistência do solo) e matéria orgânica $(\mathrm{C}, \mathrm{N}$ e EsC de 0 a $30 \mathrm{~cm}$,) influenciadas pelo uso do solo. Para avaliar as características físicas do solo serão coletadas amostras de solos em cilindros para avaliação da densidade. Serão também realizados testes de infiltrabilidade da água segundo o protocolo Beerkan simplificado. Serão feitas análises estatísticas multivariadas para evidenciar as variáveis mais relevantes dos efeitos das práticas na evolução do solo e análise univariável para descrever a variação/variabilidade das propriedades do solo mais sensíveis às mudanças de uso da terra e testar a influência dos fatores "práticas" e "solo". Espera-se quantificar as evoluções de várias propriedades do solo em determinadas condições iniciais e de uso da terra. Bem como, evidenciar as práticas mais sustentáveis a respeito da produção de bens e serviços ecossistêmicos.
\end{abstract}

PALAVRAS-CHAVE: Amazônia, meio físico, uso do solo, agricultura familiar. 